Information Engineering Express

International Institute of Applied Informatics

2019, Vol. 5, No.1, 1 - 10

\title{
The role of the Product platform in the Service System Architecture: Case Studies of Mobile Health Devices Using Smartphones
}

\author{
Toshinobu Ohnishi *, Michitaka Kosaka *
}

\begin{abstract}
A service platform has a modular structure that consists of resources in a service system and plays an important role of facilitating the interaction among stakeholders for value creation and liquefying and bundling their resources. Resource liquefaction and bundles in a service platform has a common concept in a product platform. Both platforms have building relationship by modules as devices or resources in common. Through focusing on common point, we can refer to ingredients of a product platform in a service system and relationship between a product platform and a service system. In this research, we evaluated the role of a product platform in a service system through multiple case studies. As findings in this research, resource liquefaction by a product platform facilitates modification of stakeholders' role and resource bundles by a product platform facilitate coordination of resources and community integration. Also, a product platform in a service system has a role of integrating and coordinating modular and sub-service systems and facilitates forming a service system and actors' value creation.
\end{abstract}

Keywords: Service System, Service Platform, Resource Liquefaction, Resource bundles.

\section{Introduction}

Recently, to meet the customers' needs, ICT has the architecture of products changing. Smartphones have devices such as communication apparatus, displays and cameras and applications for taking information. So, the architecture of products such as smartphones has the functions to get the data and to transform the information, and the application to utilize the data and information. The transitions in the role of products indicate that articles as product and information as function could be divided by ICT, and that it becomes important for products to transmit service value to stakeholders in a service system. The service system is defined as "self-contained, self-adjusting systems of mostly loosely coupled social and economic (resource-integrating) actors connected by shared institutional logics and mutual value creation through service exchange" in Service Dominant Logic (SDL)[1]. Value is created in use of propositions by the integration and application of resources in a specific context [1]. As the

\footnotetext{
* Japan Advanced Institute of Science and Technology, Ishikawa, Japan
} 
products in ICT facilitate connecting resources and stakeholders in a service system through the products by their resources (ex. knowledge and skills).

In a service system, a service platform leverages resource liquefaction and resource bundles and influences interacting actors [2]. The resource liquefaction builds new stakeholders' relationship and resources bundle enhances interaction between stakeholders. The functions of resource liquefaction and resource bundle are likewise involved in the product platform and product architecture. The sub-systems or layers are deployed among some products in the product platform to liquefy the functional elements [3]. In this way, resource liquefaction and resource bundle is common concept between a service platform and a product platform.

From the viewpoints of resource liquefaction and bundles, we consider that the position of products as inter-mediators for integrating resource could become clear. Also, division of functions in products indicates the change of architecture of products. Thus, it is required that the existed product platform for efficiency of value chains and product provision to a variety of segments is changed to a new product platform responding to a service system. In brief, service providers get competitive advantages from not only creating function values of products but also designing value-in-use in the service system [4]. The service providers need to improve capability of designing the product platform or product architecture as a space to create service value in the service system. Anderson indicates to transform architecture corresponding to changes of circumstances creates opportunities for new innovations [5]. Whereas, the architecture of ICT infrastructure was proposed not from the point of value creation but the component of product [2]. In SDL, the importance of the products is recognized [1], but the role of the products in a service system has not become clear.

Accordingly, we discuss the architecture of a service system for the value of various stakeholders by building relationship. From multiple case studies, we analyze the components of a product platform in terms of resource liquefaction and bundles, where we focus what roles of the products is in the information transfer among stakeholders in a service system and what sub-systems are connected in a service system. In this paper, we demonstrate the service architecture including a product platform in a service system and propose a model to construct a product platform responding both to enhance function of products and to correspond to a service platform in terms of resource liquefaction and resource bundle.

\section{Resource Liquefaction and Resource Bundles in a Product Platform and a Service Platform}

\subsection{The Modular Architecture in a Product Platform}

The product platform optimizes supply chain and appropriate adjustment to segments of customers. The product platform relates to product architecture composing of functional modules and layers or sub-systems of products and product portfolio classifying products responding to customer needs [3][6]. The product platform has two aspects [3]. One is to aggregate existing modules as function elements in products, which are common in some products [7], another is the interface among sub-systems to effectively develop derivative products by synchronizing customer needs and functions of products [8]. 
It is possible to design products matching customer needs by compounding modules representing functions in such as a product platform. Also, it is easier to distribute information by modules among in the organization, because modules indicate the characteristic as functions. Furthermore, as product developers can interact their ideas and knowledge with information of modules, the firms can provide products having high competitive advantage. The product platform consists of modular architecture and interfaces of modules and sub-systems [3].

\subsection{The Modular Architecture in a Service Platform}

The Service platform in a service system, to be similar to a product platform, is proposed in SDL. While function and utility as value for customers is embedded in products, service is represented as the process creating value to integrate the value proposed by firms with customers' knowledge and skill [4]. Products in SDL indicate medium exchanging value in FP3 [1] and service is the value creation process applying to the context of users and their stakeholders [9].

As referred to above, the service platform has relevance to a service system in configuration of resources for creation of service value [2]. A service system is composed of resources for value creation, which are modules facilitating the interaction between actors for value creation and resources [11]. To enhance the interaction between stakeholders for value creation, in a service platform, resources are composed of modules in some layers [10], and through facilitating creating value applying to stakeholders' context, it is expected that opportunities for enhancing resource liquefaction for value creation and resource bundles expand. To create value appropriate resources should be chosen for resource liquefaction and by bundling these resources value creation could be enhanced [2].

In a service system, to enhance the value-in-context reciprocally, networks of stakeholders and some sub-service system are utilized [10]. Service providers provide this high order sub service systems, which enhance building relationship for customers' value. To increase value-in-context reciprocally, their resource are liquefied and then are bundled [2]. So, the role of a product platform is to liquefy and bundle their resources in response to customer context.

\subsection{Common Concept in a Product Platform and a Service Platform}

As an ICT product has resources liquefied and bundled to provide useful information to various stakeholders, it plays an important role in a service platform. To develop products for facilitating value creation in a service system, service providers have to design a service platform for resource liquefaction and resource bundle. Resource liquefaction and resource bundle is a common concept in both a service platform and a product platform. Still, modules in a service platform are defined tangible or intangible knowledge and skill combining other resources [1], this definition is common to a product platform, too [3]. Furthermore, the interface among modules is a common concept in both a service platform and a product platform, and could provide the relation among modules. The interface facilitates resource liquefaction and bundles [3].

Considering the commonality between a service platform and a product platform and indicating the role of the products as modules in a service platform, we could gain a principal of product development for service innovation. As value in service depends on the context when the provided service is used [1], the service system is comprised of modules, and sub-systems to understand stakeholders' context [1]. Accordingly, we indicate the role of a product platform as the service platform in a service system from viewpoints of relation among resources. 


\section{Research design: aim and method}

This research aims to propose a new architecture of a service system indicating the role of products from the viewpoint of resource liquefaction and resource bundles. We focus our analysis on the relation between resources of stakeholders and modules of smartphones and the position of smartphones in the service system. Moreover, we analyzed resource liquefaction and resource bundle in the product platform and relation among resources of stakeholders in the service system.

Considering the nature of the subject matter under investigation, this study uses a qualitative method that utilizes multiple case studies. As several researchers note qualitative methods are useful for obtaining a novel understanding of existing phenomena [12][13].

To investigate the relationship between products and stakeholders in a service system, we chose the companies providing mobile health devices. We have two reasons for choosing such companies. One reason is that the mobile health devices are involved in the service system that has several stakeholders, for example, doctors, patients, pharmacies, and government. Another reason is that the recent mobile health devices embed the sensors and devices as modules. The companies were chosen through an internet search for companies which provide some products and have published the journals or research papers to investigate the relation and the activity with the stakeholders.

In case studies, we describe some cases by using the system chart which expresses the relation between stakeholders and products and analyzed the service system in the term of resource liquefaction and resource bundle; whether the functions of the products are divided or combined, how the function of products or the information about products is shared among resources, and how the divided and combined resources changed the structure of the service system. Therefore we showed elements in a service system by following table.1.

Table.1 the diagram in service chart

\begin{tabular}{|c|c|c|c|}
\hline $\begin{array}{c}\text { Products \& } \\
\text { Stakeholders }\end{array}$ & $\begin{array}{c}\text { Sub-System } \\
\text { Layer }\end{array}$ \\
\hline $\begin{array}{c}\text { Liquefied } \\
\text { Products \& } \\
\text { Stakeholders }\end{array}$ & & $\begin{array}{l}\text { Liquefied Sub- } \\
\text { System Layer }\end{array}$ & \\
\hline $\begin{array}{c}\text { Bundled } \\
\text { Products \& } \\
\text { Stakeholders }\end{array}$ & $\left(\begin{array}{l}\text { Bundled Sub- } \\
\text { System Layer }\end{array}\right.$ \\
\hline
\end{tabular}

\section{Findings in case studies}

We demonstrate four cases of mobile health devices, where roles of modules of smartphones are explained from the point of resource liquefaction and resource bundles.

\subsection{Case 1: Bundled sub-systems and resource bundles}


As ICT enhances transfer of information, stakeholders in the service system easily share their information, and thereby interaction among stakeholders could be facilitated. The enhancement of sharing information leads to resource bundle by providing useful information for stakeholders. We explain "chk4.me" such as an example. The service of "chk4.me" is the information the sharing system among healthcare providers involving patients having "Medicine Notebook", where patients' records for taking medicines based on the doctors' writing prescription have mentioned. Recently, patients access records of their own Medicine Notebooks through the internet services. Doctors and pharmacies are only allowed to access the patients' records. Also, the records in the Medicine Notebooks are not allowed to share among different Medical Notebook service providers. But, by using "chk4.me", the records of patients in the Medical Notebook are allowed to access among some other Medical Notebook service providers. (Figure 1) The cooperation among providers leads to many opportunities of the access of various pharmacies. Furthermore, as patients' families, doctors and pharmacies that patients have not used are allowed to access the records, health care providers can always deal with patients corresponding to their condition or information.

As mentioned above, "chk4.me" provides the opportunities building relationship to patients' stakeholders by their Medicine Notebook and integrate some Medicine Notebook service providers. So, the service platform bundled stakeholders about Medicine Notebook and shared information among service providers, where indicated medical notebook providers share information among resources. That is, in the case of "chk4.me", the role of products is to bundles stakeholders and to provide opportunities of selecting service provides and the service system is formed by bundled sub-systems.

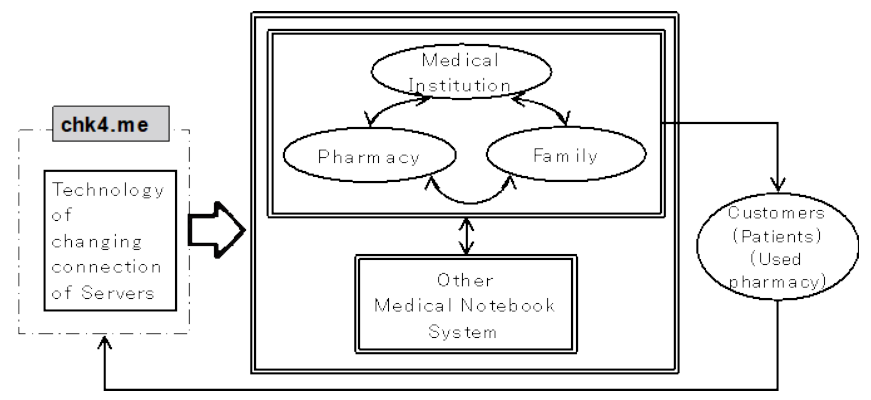

Figure.1 Service Chart of "chk4.me"

\subsection{Case 2: Resource Bundles \& Utilized Relation among Sub-systems}

Cellscope are a system of the microscopes utilizing the cameras in smartphones, and are used for pathology, education and oceanography. Furthermore, by utilizing the core technology of optics in microscopes, otoscopes were also developed. To develop products relevant to users, co-tests were tried. For example, to suppose that doctors in developing countries who are not pathologists and don't usually use microscopies, the firm asked junior high school students try to use their prototype microscopies for collecting information about using the microscopies.

The service system in Cellscope consists of the product platform corresponding to user needs, and sharing information about the situation of using products through co-test among organization. (Figure 2) In the co-test projects, Cellscope shares the information and evaluation of students' usage condition among other projects. It is useful for the projects to develop microscopes 
in response to different customer needs. The shared information among the projects is liquefied in response to different customer needs, and bundled with technology in the projects for various developing products among the product platform. So, the product platform includes sharing information and information bundles and technology as core competence. In case of Cellscope, the product platform has relation to customers in segments in the sub-system layers in the service system and plays a role as an inter-mediator for resource bundles such as core competence and users' evaluation.

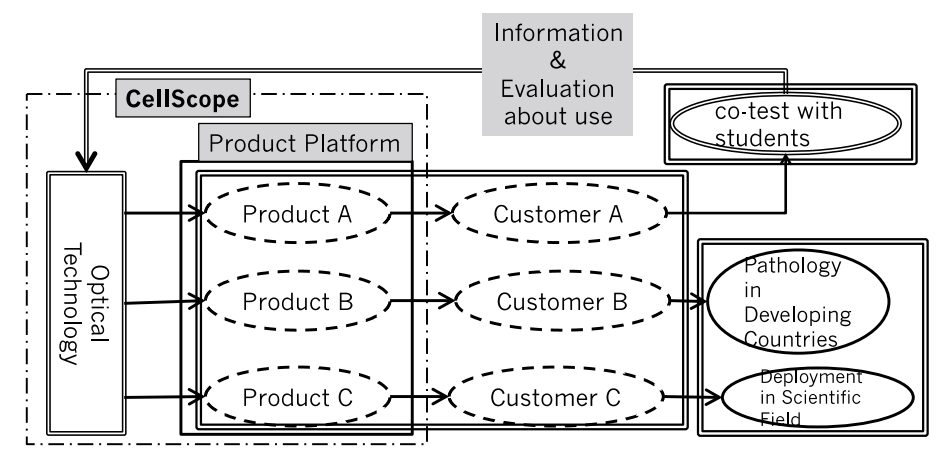

Figure 2 The Service Chart in Cellscope

\subsection{Case 3: Resource liquefaction by inter-mediators and resource bundles by a product platform}

EyeNetra provides the ophthalmoscope, inspection equipment and lens meters on the basis of technology in optics. So far, in America, when patients buy glasses, they should get their prescriptions that a ophthalmologist makes out by using above devices and then need to go to an optician's shop with their prescriptions. (Figure 3) To make the process much effort of patients easy, EyeNetra constructed the product platform by independently developing required technique. (fig.3) Furthermore, these devices were installed in an optician's shop, and patients measure indexes of their eyes by themselves using these devices. Then, an ophthalmologist should be present at patients' measurement in order to confirm whether the measurement is proper. So, the role of ophthalmologist and patients has changed in making prescriptions and examination.

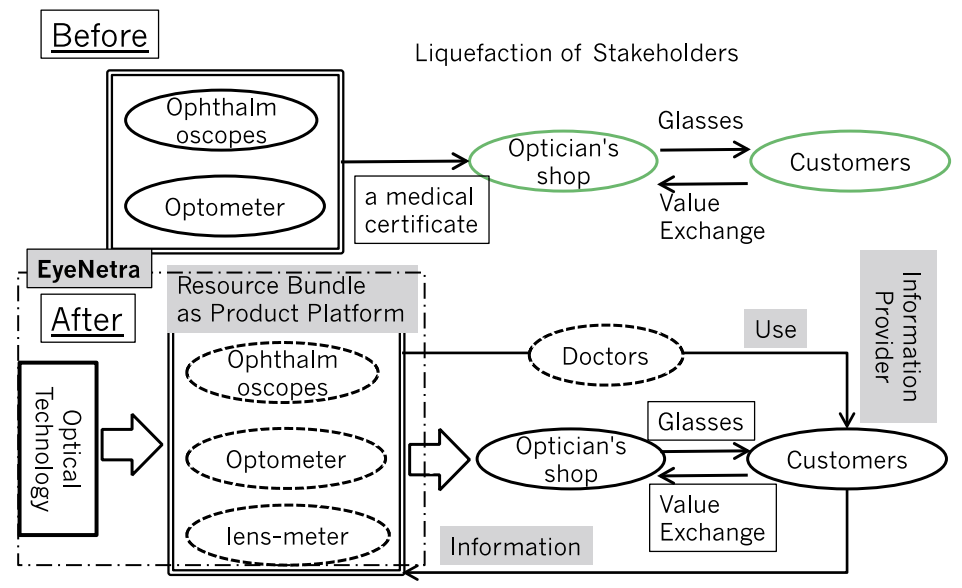

Figure 3 The Service Chart in Eyenetra 
In service system of this case, the role of doctors and patients has changed by using devices in the product platform. The role of stakeholders was liquefied in the service system. In EyeNetra, service providers to patients are changed from optician's shop and doctors to optician's shop and EyeNetra. This means that the products have the role of stakeholders liquefied and resource bundled in the product platform as a sub-system in the service system. Until EyeNetra provided the service, the prescriptions used to be handled from doctors to optician's shop. But EyeNetra makes the role of optician' shop co-operator with patients. The product platform in EyeNetra causes a change of the role of optician's shop.

\subsection{Case 4: Resource liquefaction for changing the role of stakeholders}

It is important to liquefy the role of stakeholders especially in communities as a sub-system in the service system, thereby the product platform needs to play an important role in the service system. Peekvision has the product platform composed of the ophthalmoscope and opt meters, and provides medical services with the medical communities by utilizing this product platform. (Figure 4)

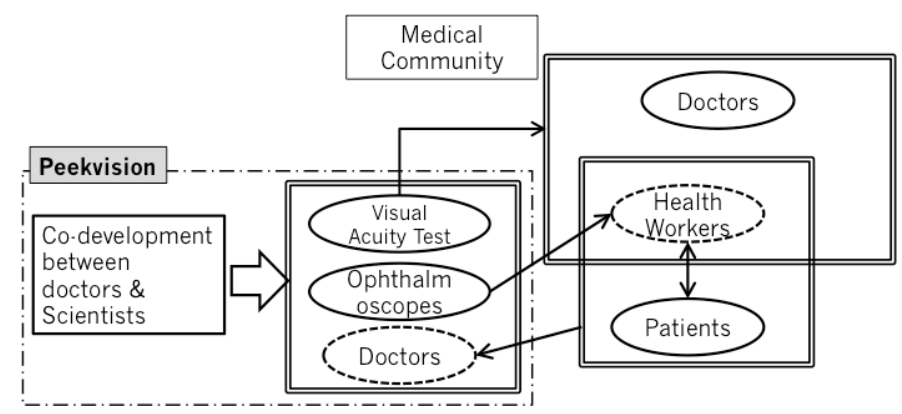

Figure 4 The service chart in Peekvision

In Peekvision, the trained health care providers examine patients' eyes by using the ophthalmoscope utilizing the cameras of smartphones and sent information about examination data and the situation of examination. Doctors diagnose with information gained from the ophthalmoscope through the network system. Also, health care providers belong to the medical communities, and are engaged in hospital practice by utilizing some medical equipment with devices in Peekvision.

The ophthalmoscope in Peekvision divides the examination with diagnose, where both were the doctor's role. The products made doctor's roles liquefied and trained health workers played new role of integrating sub-systems as intermediates. Also, Peekvision made medical communities by providing the product platform. Furthermore, the information of examination by tele-medicine doctors was fed back to doctors in a medical community and shared. So, in Peekvision, the product platform liquefies the role of stakeholders such as doctors and health workers according to sub-systems. Then the liquefaction leads to sub-systems bundles by intermediators as health workers.

\section{Discussion}

Based on the above cases, we consider the role of a product platform in the service system in terms of resource liquefaction and resource bundles and the relation among sub-systems. 
We found that the product platform led to resource liquefaction and resource bundles in a service system. The product platform supports to construct relationship among stakeholders and bundle stakeholders as resources in a service system in case of "chk4.me". Also, the product platform led to bundle core competence and information about the situation of using products by sharing among organization in Cellscope. As for resource liquefaction, in EyeNetra, the role of ophthalmologists was transported by some devices in the product platform, and the role of ophthalmologists is liquefied. The changing role of ophthalmologists was operated in Peekvision.

The resource liquefaction and bundles in the product platform build the relation among sub-systems in a service system changes: to structure the new relationship among sub-systems and to utilize the existed sub-systems. As for structuring new relationship among sub-systems, in Peekvision, products provide the inter-mediators and stimulate them to bundle the communities in different sub-systems. Also, in "chk4.me", by integrating stakeholders and bundling the some health notebook service providers, the service system was structured by layered sub-systems. As for utilizing the existed sub-systems of a product platform, in Cellscope, resource of stakeholders are bundled among a product family. Also, in EyeNetra, the products liquefy the role of doctors in the existed sub-systems as relationship among stakeholders.

We summarize a service system in terms of the role of a product platform and the relation among sub-systems (Figure 5). In this manner, service systems are classified into four sections.

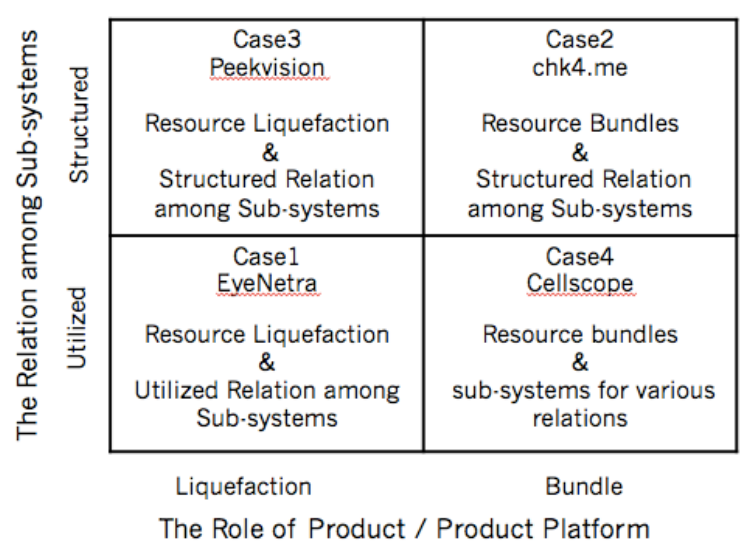

Figure 5 The Classification of the Service System

From the classification, we consider a service system is composed of modules such as resources, stakeholders and information (Table 2). Especially, information is an important factor in not only the role of a product platform but also the relation among sub-systems. Information stimulates the role of the modules to change by liquefaction and bundles.

In the product architecture, the combination of modules and decomposition of modularity provide the function of the product [14], on the other hand, in the service architecture, the value chain enhances the change the configuration of a service system. On the basis of information for building relationship among stakeholders, modules in a service system are liquefied and integrated and the configuration of sub-systems changes relationship between stakeholders for value chains. The service systems could correspond to diverse value of stakeholders. To make the resource liquefaction and bundles effective, sub-service systems need to make function to correspond to stakeholders' context [1]. The product platform in a service system facilitates not only 
the interaction of stakeholders, but also the interaction of information and stakeholders.

Table 2 The role of modules of the Service Architecture

\begin{tabular}{|l|l|l|}
\hline \multicolumn{1}{|c|}{ Role } & \multicolumn{1}{|c|}{ Modules } & \multicolumn{1}{c|}{ Methods } \\
\hline \multirow{2}{*}{$\begin{array}{l}\text { Building Relationship } \\
\text { among Stakeholders }\end{array}$} & Product Platform & $\begin{array}{l}\text { - Changing the roles of } \\
\text { stakeholders } \\
\text { Sharing information among } \\
\text { stakeholders }\end{array}$ \\
\cline { 2 - 3 } & Resources & - Resource Liquefaction \\
\cline { 2 - 3 } $\begin{array}{l}\text { Stakeholders } \\
\text { Value Creation }\end{array}$ & $\begin{array}{l}\text { Forming Community to share } \\
\text { information } \\
\text { Value Chain }\end{array}$ & $\begin{array}{l}\text { Changing the role of } \\
\text { stakeholders }\end{array}$ \\
\cline { 2 - 3 } & Resources & $\begin{array}{l}\text { Changing Configuration of } \\
\text { Service System }\end{array}$ \\
\cline { 2 - 3 } & Resource bundle \\
\hline
\end{tabular}

\section{Conclusion}

In this research, we focus the resource liquefaction and resource bundles of the service platform in a service system and demonstrate the configuration of the product platform having the same function as the service platform. Based on findings from cases, we propose the architecture of the service system, which is composed of the product platform, stakeholders and resources. We assume the product platform facilitates changing the roles of stakeholders and sharing information by the inter-mediators through the resource liquefaction, and enhance the cooperation of the resources, sharing information, and the formation of communities through the resource bundles. The operation of a product platform enhances formation of a service system for creating value in service.

In the cases of this research, we choose the companies developing the unique technology on the basis of the mobile platform. In such a service system, technology is applied in term of Service Dominant Logic as well [8]. We presume that the relationship between the product platform and its role for the servitization is important [15]. For the future issue in this article, we need to research the relationship between modules in the product platform and a service system in detail using more cases.

\section{References}

[1] S. L. Vargo and R. F. Lusch, "It's All B2B... and Beyond: Toward a Systems Perspective of the Market," Industrial Marketing Management, vol.40, 2011, pp.181-187.

[2] R. F. Lusch and S. Nambisan, "Service Innovation: A Service-Dominant Logic Perspective," Mis Quarterly, vol.39, no.1, 2015, pp.155-175.

[3] J. R. Jiao, T. W. Simpson and Z. Siddique, "Product family design and platform-based product development: a state-of-the-art review," Journal of intelligent Manufacturing, vol,18, no.1, 2007, pp.5-29.

[4] R. F. Lusch and S. L. Vargo, "Service-dominant logic: reactions, reflections and refinements," Marketing theory, vol.6, no.3, 2006, pp.281-288. 
[5] R. M. Henderson and K. B. Clark, "Architectural innovation: The reconfiguration of existing product technologies and the failure of established firms," Administrative science quarterly, 1990, pp.9-30.

[6] R. G. Cooper, S. J. Edgett and E. J. Kleinschmidt, "New product portfolio management: practices and performance," Journal of product innovation management, vol.16, no.4, 1999, pp.333-351.

[7] K. Ulrich, "The role of product architecture in the manufacturing firm," Research policy, vol.24, no.3, 1995, pp.419-440.

[8] C. Y. Baldwin and K. B. Clark, "Design rules: The power of modularity," MIT Press,2000.

[9] M. A. Akaka and S. L. Vargo, "Technology as an operant resource in service (eco) systems," Information Systems and e-Business Management, vol.12, no.3, 2014, pp.367-384.

[10] M. A. Akaka, S. L. Vargo and R. F. Lusch, "The complexity of context: a service ecosystems approach for international marketing," Journal of Marketing Research, vol.21, no.4,2013, pp.1-20.

[11] S. L. Vargo, P. P. Maglio, and M. A. Akaka, "On value and value co-creation: A servicesystems and service logic perspective," European management journal, vol.26, no.3, 2008,pp.145-152.

[12] R.K. Yin, Case Study Research, Applied Social Research Methods, Sage, 2002.

[13] K. M. Eisenhardt, "Building theories from case study research," Academy of management review, vol.14, no.4, 1989, pp.532-550.

[14] H. Wieland, F. Polese, S. L. Vargo and R. F. Lusch, "Toward a service (eco) systemsperspective on value creation," International Journal of service Science, Management, Engineering, and Technology, vol.3, no.3, 2012, pp.12-25.

[15] C. Kowalkowski, "What does a service-dominant logic really mean for manufacturing firms?" CIRP Journal of Manufacturing Science and Technology, vol.3, no.4, 2010,pp.285-292. 